\title{
Clinical Profile of MDR-TB patients with special reference to kanamycin induced ototoxicity in a tertiary care hospital of eastern India
}

\author{
Ghosh S. ${ }^{1}$, Gayen P. ${ }^{2 *}$, Halder A. ${ }^{3}$, Bandyopadhyay R. ${ }^{4}$ \\ DOI: https://doi.org/10.17511/ijmrr.2019.i03.12 \\ ${ }^{1}$ Saswata Ghosh, Assistant Professor, Department of Chest Medicine, Malda Medical College and Hospital, Malda, West Bengal, India. \\ 2* Prosenjit Gayen, Assistant Professor, Department of Pathology, Malda Medical College and Hospital, Malda, West Bengal, India. \\ ${ }^{3}$ Atish Halder, Assistant Professor, Department of ENT, Malda Medical College and Hospital, Malda, West Bengal, India. \\ ${ }^{4}$ Ramtanu Bandyopadhyay, Professor, Department of General Medicine, Malda Medical College and Hospital, Malda, West Bengal, India.
}

Introduction: MDR-TB is defined as resistance to isoniazid and rifampicin, with or without resistance to other anti-TB drugs. Multidrug-resistant TB (MDR-TB) remains a public health crisis and a health security threat. Kanamycin, is an aminoglycoside antibiotic used to treat multi-drug resistant TB in the intensive phase. Objective: To analyze the patients of MDR-TB with respect to age, sex and presence of comorbidities like diabetes mellitus. Also to study the incidence of hearing impairments among patients of MDR-TB receiving injectable Kanamycin. Methods: 40 patients of MDR-TB diagnosed by sputum culture and drug susceptibility testing (DST) have been classified on the basis of age, sex and presence of diabetes mellitus. All have received injectable Kanamycin for 6 months in their intensive phase (IP). Patients giving history of auditory impairments underwent pure tone audiometry (PTA) for detection of sensory neural hearing loss, if any. Result: Out of 40 patients of MDR-TB, 30 were males and the rest 10 were females. Age ranges from 12 to 70 years among which maximum patients fell in the age group of 21-30 years (12 patients). 16 patients were diabetic. After getting Kanamycin, 8 patients gave the history of auditory disturbances and only 1 patient found to have severe sensory neural hearing loss confirmed by pure tone audiometry.Conclusion: Prevalence of MDR-TB has been found more among males and in younger age group. Diabetes Mellitus play a major role here. Kanamycin induced hearing loss is not a very serious concern in our study.

Keywords: Deafness, Kanamycin, Pure tone audiometry, Multidrug-resistant tuberculosis

Corresponding Author

Prosenjit Gayen, Assistant Professor, Department of Pathology, Malda Medical College and Hospital, Malda, West Bengal, India.

Email: sneha1611.ag@gmail.com
How to Cite this Article

To Browse

Ghosh S, Gayen P, Halder A, Bandyopadhyay R.

Clinical Profile of MDR-TB patients with special reference to kanamycin induced ototoxicity in a tertiary care hospital of eastern India. Int J Med Res Rev. 2019;7(3):218-223.

Available From

https://ijmrr.medresearch.in/index.php/ijmrr/article/

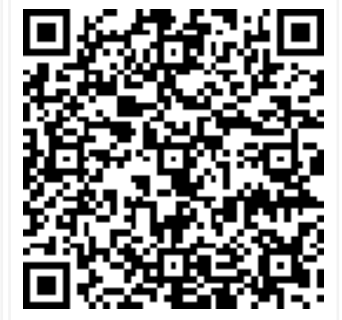
view/1062

Manuscript Received 2019-05-20

Conflict of Interest No
Review Round 1 2019-05-30

Funding

$\mathrm{Nil}$

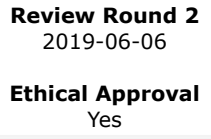

Ethical Approval Yes

Review Round 3

Plagiarism X-checker $7 \%$
Accepted 2019-06-11

Note

(c) 2019 by Saswata Ghosh, Prosenjit Gayen, Atish Halder, Ramtanu Bandyopadhyay and Published by Siddharth Health Research and Social Welfare Society. This is an Open Access article licensed under a Creative Commons Attribution 4.0 International License hittps://creativecommons.org/licenses/by/4.0/ unported [CC BY 4.0]. 


\section{Introduction}

Multi Drug Resistant TB is often abbreviated to MDR-TB. Multidrug-resistant tuberculosis (MDR-TB) is a form of TB caused by bacteria that do not respond to isoniazid and rifampicin, the 2 most powerful, first-line anti-TB drugs [1]. MDR-TB is treatable and curable by using second-line drugs.

However, second-line treatment options are limited and require extensive chemotherapy (up to 2 years of treatment) with medicines that are expensive and toxic. For many years Multi Drug Resistant TB (MDR) has been the most basic form of drug resistant TB. In 2017, MDR-TB remains a public health crisis and a health security threat. WHO estimates that there were 558000 new cases with resistance to rifampicin - the most effective firstline drug - of which $82 \%$ had MDR-TB [2]. The MDR-TB burden largely falls on 3 countries - India, China and the Russian Federation- which together account for nearly half of the global cases and the type of TB for which many statistics were collected [2].

There are two main ways that one can get MDR TB. Firstly one can get it if he doesn't take drugs exactly as have been instructed by health care provider. One can also get MDR if he gets TB bacteria from another person who already has MDR-TB. This is known as primary TB. It used to be believed that most people had acquired TB, but now-a-days more and more cases of primary TB have been detected. Kanamycin is an aminoglycoside antibiotic used to treat several bacterial infections. It is used to treat multidrug resistant TB as well. Kanamycin, discovered in 1957, is used as part of a treatment regimen, usually involving 5 medicines, to treat MDR TB. It is part of a group of medicines called injectable. [3,4]. Kanamycin is administered via intramuscular injection for at least six months during the intensive phase of treatment. When necessary, Kanamycin may be continued during the continuation phase, administering the same dose 2 to 3 times weekly.

Mode of action: Kanamycin is an aminoglycoside antibiotic isolated from Streptomyces kanamyceticus. Kanamycin inhibits protein synthesis by binding to the $70 \mathrm{~S}$ ribosomal unit, making TB unable to grow.

\section{Dosage of Kanamycin in MDR-TB[5]}

16-29kg. $30-45 \mathrm{~kg} \cdot 46-70 \mathrm{~kg} .>70 \mathrm{~kg}$

$500 \mathrm{mg} .750 \mathrm{mg} .750 \mathrm{mg} .1000 \mathrm{mg}$
Side effects: Injectable including kanamycin can cause damage to the kidneys. Creatinine levels should be monitored in patients with kidney damage. Kanamycin is generally safe in patients with liver disease; however, it should be used with caution, as it may cause rapid progression of hepatorenal syndrome (kidney failure in a person with cirrhosis of the liver) in patients with severe liver disease .Kanamycin can also cause loss of hearing, dizziness, peripheral neuropathy, pain at the injection site and rashes. Kanamycin should not be taken during pregnancy, unless as a last resort, as it may cause deafness in the infant.

\section{Objectives}

1. To analyze the patients of MDR-TB with respect to age, sex and presence of comorbidities like diabetes mellitus.

2. To study the incidence of hearing impairment among patients of MDR-TB receiving injectable Kanamycin.

\section{Methods}

Study Type: Hospital based Cross-sectional Observational study.

Sample Size: Total 40 patients with MDR-TB were enrolled.

Sampling technique: Consecutive non probability technique used

Inclusion Criteria: Patient diagnosed with MDR-TB by sputum culture and drug susceptibility testing (DST). Both males and females above the age of 12 years attending OPD of Chest Medicine and District Tuberculosis Centre, Malda Medical College and Hospital.

Exclusion Criteria: 1) Patients having only Rifampicin resistance, 2) Patients of XDR-TB, 3) Patients unwilling to join the study.

Study Procedure: The study commenced after obtaining permission from Institutional Ethical Committee and written informed consent from patients. Patients were selected with a diagnosis of MDR-TB by Sputum culture and DST. A detailed history and thorough clinical examination was done.

Pure tone audiometry were performed before the start of therapy and was repeated after 2 months and 6 months of Kanamycin use to assess hearing loss due to this drug. 
Place of study: a) OPD of Chest Medicine and District Tuberculosis Center, Malda Medical College and Hospital, Malda, West Bengal.

\section{Results and Analysis}

A total of 40 patients of MDR-TB who were receiving Injection Kanamycin were included in this study. The key baseline characteristics are listed in the table below:

Table-1: Age distribution among MDR-TB patients as follows

Age distribution of the patients shows that maximum number of patients are in the age group $21-30$ years (30\%) followed by group $31-40$ years $(25 \%)$.

\begin{tabular}{|l|l|l|}
\hline \multicolumn{1}{|c|}{ Age in years } & Number of cases & percentage (\%) \\
\hline $12-20$ & 4 & 10 \\
\hline $21-30$ & 12 & 30 \\
\hline $31-40$ & 10 & 25 \\
\hline $41-50$ & 8 & 20 \\
\hline $51-60$ & 4 & 10 \\
\hline $61-70$ & 2 & 5 \\
\hline
\end{tabular}

Table-2: Gender distribution among MDR-TB patients as follows

\begin{tabular}{|l|l|l|}
\hline \multicolumn{1}{|c|}{ Gender } & Number of cases & \multicolumn{1}{c|}{ Percentage (\%) } \\
\hline Male & 30 & 75 \\
\hline Female & 10 & 25 \\
\hline
\end{tabular}

Table-3: Prevalence of Diabetes Mellitus in the study group

\begin{tabular}{|l|l|}
\hline Number of Diabetic cases & Percentage (\%) \\
\hline 16 & 40 \\
\hline
\end{tabular}

Table-4: Prevalence of Kanamycin induced auditory impairment in the study group

\begin{tabular}{|l|l|}
\hline \multicolumn{1}{|c|}{ Number of auditory impairment cases } & Percentage (\%) \\
\hline 8 & 20 \\
\hline
\end{tabular}

Table-5- Prevalence of Kanamycin induced sensory neural deafness in the study group.

\begin{tabular}{|l|l|}
\hline \multicolumn{1}{|c|}{ Number of sensorineural deafnesscases } & Percentage (\%) \\
\hline 1 & 2.5 \\
\hline
\end{tabular}

Image-1- Classification of hearing loss on the basis of pure tone audiometry: Pure tone audiometric air conduction testingis performed by presenting a pure tone to the ear through an earphone and measuring the lowest intensity in decibels $(\mathrm{dB})$ at which this tone is perceived $50 \%$ of the time. This measurement is called threshold. The testing procedure is repeated at specific frequencies from 250 to 8000 hertz ( $\mathrm{Hz}$, or cycles per second)
For each ear, and the thresholds are recorded on a graph called an audiogram [6].

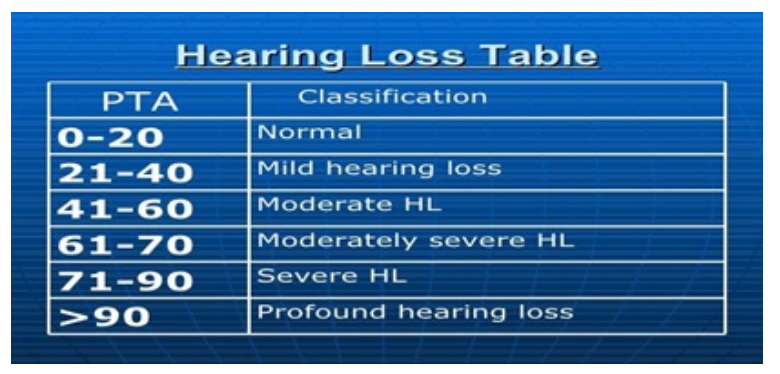

Image-1- Classification of hearing loss on the basis of pure tone audiometry

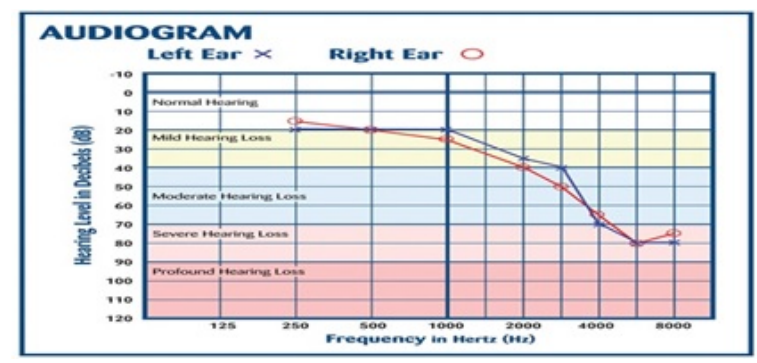

Image-2- Standard classification of hearing loss in both ears showing in Audiogram

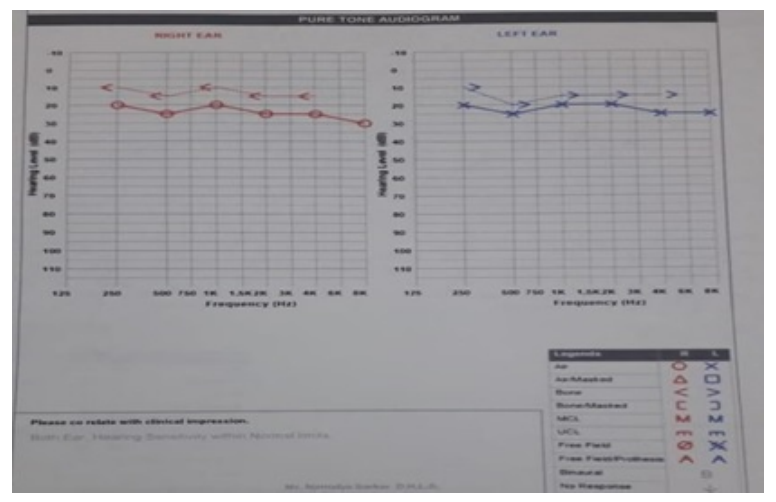

Image-3- Patient in our study group having normal Audiogram

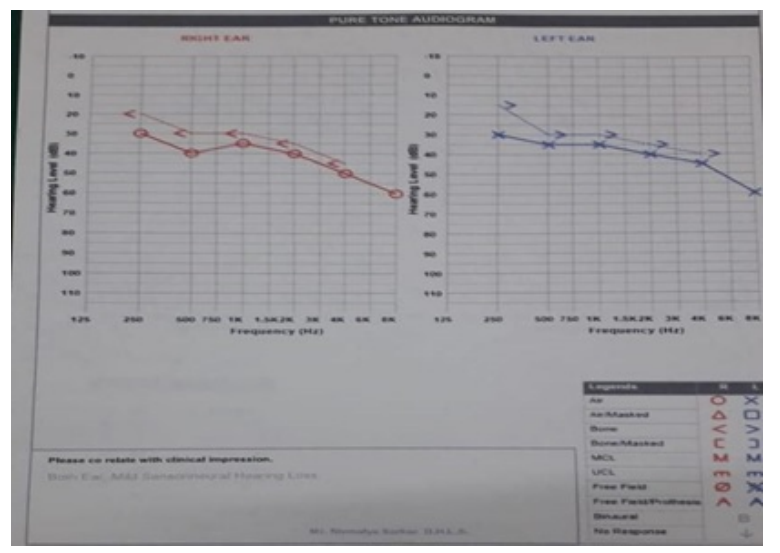




\section{Image-4- Patient in our study group having mild auditory loss}

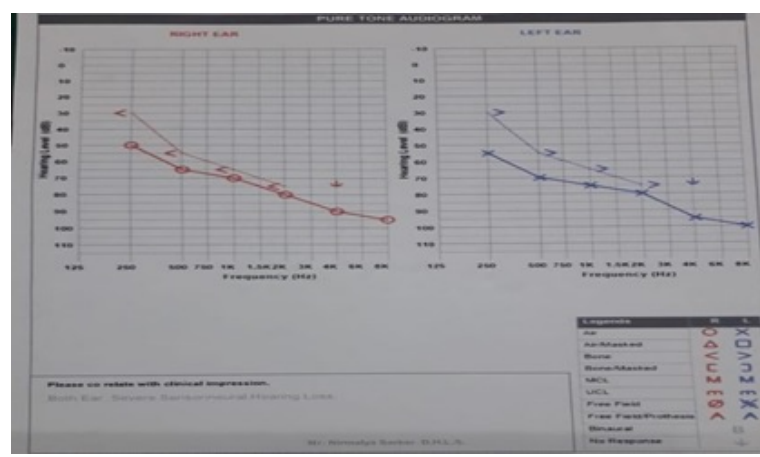

Image-5: Only patient in our study group showing sever sensoryneural hesring loss and Kanamycin had been stopped subsequently

\section{Discussion}

Our study has been compared with those of the other studies of MDR-TB and Kanamycin induced hearing impairment in various parts of the world. Analysis of the age distribution in our study showed that maximum number of patients are in the age group 21-30 years (30\%) followed by group 31-40 years $(25 \%)$. One study in Taiwan showed that cases above 65 years of age accounted for $27.4 \%$ (13.7\%-37.1\%) of the total MDR- TB cases, followed by $20.0 \%$ and $21.8 \%$ for the $55-64$-yearold and 45-54-year-old age groups, respectively [7]. A study from Ahmedabad, India, in which $83.7 \%$ of patients were in age group of $16-45$ years with a mean age of $33.64 \pm 11.03$ [8].

Gender distribution in our study is in the ratio of $3: 1$ for male and female. Over the past twenty years, tuberculosis (TB) case notifications among men have exceeded those among women in most settings. In 2014, the male-to-female (M:F) ratio in smear-positive pulmonary TB case notification was 1.7 globally and ranged from 1.0 in the Eastern Mediterranean Region to 2.1 in the Western Pacific Region. The excess of notified cases among men has often been explained as a result of barriers faced by women in seeking care for and being diagnosed with TB [9].

Historically, the incidence of tuberculosis in patients with diabetes has been high. In 1934, a treatise on the association between diabetes and tuberculosis was written by Howard Root (a physician at the Deaconess Hospital, Boston, MA, USA), before the availability of antimycobacterial drugs.
His lengthy tome described the epidemiology, pathology, and clinical course of dually affected patients. In his studies, tuberculosis in adults with diabetes was more common than expected, and risk was particularly high in schoolchildren and adolescents with diabetes. $[10,11]$.

In the Philadelphia Diabetic Survey, Boucot and colleagues found a two-fold increase in prevalence tuberculosis by chest radiograph in 3106 diabetic patients compared with 70767 controls of similar demographics. Further more, they found that diabetic patients who needed more than 40 units of insulin per day were twice as likely to develop tuberculosis as those using lower doses, thus linking severity of diabetes mellitus with risk of tuberculosis. [12].

This is in accordance with our study where the prevalence of Diabetes Mellitus in MDR-TB patients where it is as high as $40 \%$. One study in China also showed strong association between DM and MDR$\mathrm{TB}$ [13] Association between diabetes mellitus and multi-drug-resistant tuberculosis has also been shown in a study conducted in Ethiopia [14]. A high proportion of individuals with multidrug-resistant tuberculosis (MDR-TB) develop permanent hearing loss due to ototoxicity caused by injectable aminoglycosides [15]. A study published in JMA also showed severe ototoxicity by Kanamycin [16].

A prospective cohort study published in European Respiratory journal by Scott K. Heysell et al in 2017 showed more than $75 \%$ patients experienced hearing loss after Kanamycin treatment whereas in our study, only $20 \%$ of patients experienced mild to moderate hearing loss and only $2.5 \%$ showed severe sensorineural deafness[17]. In our study, only $20 \%$ of patients complained about auditory disturbances among which only 1 patients found to have severe sensorineural hearing loss confirmed by pure tone audiometry.

\section{Conclusions}

- Prevalence of MDR-TB has been found more among males.

- Prevalence of MDR-TB has been found more among younger age group.

- Diabetes Mellitus has a strong association with the occurrence of MDR-TB.

- Kanamycin induced hearing loss is not a very serious concern in our study. 


\section{Outcome of this Study}

Although our study shows similar prevalence of MDR-TB on age and gender basis and a higher prevalence rate among Diabetics, contrary to Internationally acclaimed studies, our study does not show a very strong association of ototoxicity among Kanamycin users.

\section{Limitations}

01. Small number of patients were included in the study.

02. Long term follow-up could not be done to evaluate ototoxicity.

\section{Contribution by Authors}

Dr Saswata Ghosh and Dr Atish Halder: Concept designing and conducting the study.

Dr ProsenjitGayen: Conducting the study and writing the manuscript.

Prof. Ramtanu Bandyopadhyay: Guiding the study procedure and preparing the manuscript suitable for publication.

\section{Reference}

01. Dodd $P$, et al. Global burden of drug-resistant tuberculosis in children- a mathematical modelling study. The Lancet Infectious Diseases. 2016;16(10)1193-1201.

[Crossref]

02. World Health Organisation. Tuberculosis. WHO. 18 Sept; 2018.

[Crossref]

03. Prasad R, Verma SK, Sahai S, et al. Efficacy and safety of kanamycin, ethionamide, PAS and cycloserine in multidrug-resistant pulmonary tuberculosis patients. Indian J Chest Dis Allied Sci. 2006 Jul-Sep;48(3)183-6.

[Crossref]

04. Caminero JA, Sotgiu G, Zumla A, et al. Best drug treatment for multidrug-resistant and extensively drug-resistant tuberculosis. Lancet Infect Dis. 2010 Sep;10(9)621-9.

doi: $10.1016 / S 1473-3099(10) 70139-0$ [Crossref]

05. Guidelines on programmatic management of drug-resistant Tuberculosis in India. 2017Chapter7/table 7,5/page 71.

doi: 10.1016/S1473-3099(10)70139-0 [Crossref]
06. Walker HK, Hall WD, Hurst JW, et al. Clinical Methods- The History, Physical, and Laboratory Examinations. 3rd edition, BostonButterworths. 1990.

[Crossref]

07. Pei-Hua Chuang, et al. Population-Based Drug Resistance Surveillance of Multidrug-Resistant Tuberculosis in Taiwan, 2007-2014. PLoS One. 2016 Nov 15;11(11)e0165222.

doi: 10.1371/journal.pone.0165222 [Crossref]

08. Hudelson P. Gender differentials in tuberculosisthe role of socio-economic and cultural factors. Tuber Lung Dis. 1996 Oct;77(5)391-400. [Crossref]

09. Katherine C Horton, et al. Sex Differences in Tuberculosis Burden and Notifications in Lowand Middle-Income Countries- A Systematic Review and Meta-analysis. PLoS Med. 2016 Sep 6;13(9)e1002119.

doi: 10.1371/journal.pmed.1002119 [Crossref]

10. Barach J. Historical facts in diabetes mellitus. Ann Med Hist. 1928;10;387.

[Crossref]

11. Root $H$. The association of diabetes and tuberculosis. N Engl J Med. $1934 ; 210 ; 1 ; 78 ; 127$. [Crossref]

12. Boucot KR, Dillon ES, Cooper DA, Meier $P$, et al. Tuberculosis among diabetics: the Philadelphia survey. Am Rev Tuberc. 1952 Jan;65(1-2)1-50. [Crossref]

13. Liu Q, Li W, Xue $M$, et al. Diabetes mellitus and the risk of multidrug resistant tuberculosis- a meta-analysis. Sci Rep. 2017 Apr 24;7(1)1090. doi: 10.1038/s41598-017-01213-5 [Crossref]

14. Balewgizie Sileshi Tegegne et al. Association between diabetes mellitus and multi-drugresistant tuberculosis- a protocol for a systematic review and meta-analysis. Syst Rev. $2017 ; 6 ; 6$.

[Crossref]

15. Hong $H$, Budhathoki $C$, Farley JE. Increased risk of aminoglycoside-induced hearing loss in MDRTB patients with HIV coinfection. Int J Tuberc Lung Dis. 2018 Jun 1;22(6)667-674.

doi: $10.5588 /$ ijtld.17.0830 [Crossref] 
16. Joseph Satalof, Seymour Wagner, Hyman Menduke. Kanamycin Ototoxicity in Healthy Men. Arch Otolaryngol. 1964;80(4)413-417.

doi: $\quad 10.1001 /$ archotol.1964.00750040425010

[Crossref]
17. Scott K Heysell, Shahriar Ahmed, Md Toufiq Rahman, et al. Hearing loss with kanamycin treatment for multidrug-resistant tuberculosis in Bangladesh. Eur Respir J. 2018 Mar;51(3)1701778.

doi: 10.1183/13993003.01778-2017 [Crossref] 